\title{
ALOHA-93 measurements of intrinsic AGW characteristics using airborne airglow imager and groundbased $\mathrm{Na}$ Wind/Temperature lidar
}

\author{
G. R. Swenson \\ Lockheed Research and Development
}

M. J. Taylor and P. J. Espy,

Utah State University

C. Gardner and X. Tac

University of Illinois

\begin{abstract}
Monochromatic Acoustic Gravity Waves (AGWs) with periods $<1$ hour are a prevalent feature in the mesospheric airglow layers. These waves are important dynamically and energetically to the region where their temporal and spatial morphology are not well established. The purpose of this study is establish the intrinsic AGW characteristics over an extended region (as flown by the NCAR Electra aircraft) and to present the data in terms of the predicted spectral domain defined by the Brunt-Vaisala frequency and the diffusive filtering limit proposed by Gardner [1994]. On October 21, 1993, observations were made from the NCAR Electra aircraft during a 6 hour flight in a large triangle $\mathrm{N}$ and $\mathrm{W}$ of Maui, for a integral distance of $\sim 3000 \mathrm{~km}$. The entire area observed $[\sim 1 \mathrm{M}$ $\mathrm{km}^{2}$ ] had a monochromatic AGW propagating toward the NW and the westem half had a SW propagating wave superimposed. These waves were also observed with the Michelson interferometer on the aircraft and an airglow imager at the Haleakala location during this time. Intrinsic phase velocities were computed where the $\mathrm{Na}$ Wind/Temperature (W/T) lidar at Haleakala provided a measure of the mean wind to compensate phase velocities observed with the imager. The data were tabulated and plotted in an AGW spectral reference frame and compared to cutoff conditions predicted by diffusive filtering theory.
\end{abstract}

\section{Introduction}

Horizontal wavelength structure has been observed with airglow imagers from ground based sites but the Electra flights provide a new capability to observe the geographical extent of structure and to investigate wave sources. Monochromatic AGW features with periods less than 1 hour are an ever present phenomena in airglow structure at upper mesosopheric altitudes. Taylor et al. [1987] and Swenson and Mende [1994] (and references) provide data examples of monochromatic AGW structure, a frequently reported feature. In order to extract the intrinsic parameters of an AGW, the measurement of the horizontal wavelength and extrinsic period are required, where the extrinsic (apparent) AGW period is corrected for the background wind at the altitude through which the AGW is propagating [Hines and Tarasick, 1987]. Historically, horizontal wavelength and the observed period have typically been measured but coincident background wind data needed to calculate the intrinsic phase speed have been lacking. The ALOHA-93 observations of October 21 provide a measurement of the intrinsic AGW parameters over a large spatial region.

Copyright 1995 by the American Geophysical Union.

Paper number 95GL02579

0094-8534/95/95GL-02579\$03.00
The purpose of this intrinsic AGW wave parameters study is to (1) provide a sampling from a relatively large geographic region and (2), to tabulate and present the observations in an 'AGW' spectral reference frame (domain). The statistical sample from this flight is used in a separate study along with other data by Swenson et al. [this issue] to predict the upper limit to which the monochromatic waves observed in the 80 $105 \mathrm{~km}$ altitude region are capable of propagating and transferring their energy to the atmosphere. The AGW intrinsic parameters calculated here are plotted in the spectral reference frame predicted by diffusive filtering theory [Gardner, 1994]. A goal is to begin the compilation of a data base to establish a spectral domain of monochromatic AGW observations to validate spectral models. As a data base evolves, the spectral character of monochromatic AGWs can be ascertained and eventually a 'spectral climatology' can be established. This is important in order to validate AGW models as well as to provide an input into global circulation studies where AGW input are required.

On October 21, a six hour triangular flight covered an extended region NW of Haleakala, Maui while simultaneously, data was acquired from all-sky imagery and lidar systems on Haleakala. On the Electra aircraft, measurements were made with a Michelson Interferometer [OH $(3,1)$ band], an all-sky airglow imager, and the $\mathrm{Na}$ density lidar. The aspects of the ALOHA-93 campaign, the instrumentation and the observational and data analysis methods reported in this paper are summarized by Gardner [this issue] and Swenson and Espy [this issue] and references. The details of the horizontal and vertical wave number spectra inferred from the airglow imager and $\mathrm{Na}$ lidar data are presented by Gardner et al. [this issue]. This paper summarizes the nature of the monochromatic features, which were extensive throughout the flight, for the airglow data measured from the aircraft, and Haleakala. The apparent phase velocity $\left(\mathrm{C}_{\mathrm{obs}}\right)$ can be measured with the aircraft imager by observing a given AGW phase front for 10 20 minutes to establish wave position versus time. Changes in phase front position, corrected for aircraft velocity, yield the observed phase velocity, i.e. $\mathrm{C}_{\text {obs. }}$. The $\mathrm{Na}$ lidar on Haleakala measured the mean winds at airglow altitudes. The intrinsic phase velocity $\left(C_{i n}\right)$ for the aircraft measurements were then computed by $C_{i n}=C_{\text {obs }}-U$, where $U=$ the component of wind normal to the AGW phase fronts. For this study, the Haleakala Na lidar measurement of wind [Xin et al., this issue] was used for the calculation of $U$. The AGW dispersion relationship was used to calculate $\lambda_{z}$ from $C_{\text {in }}$ (described above) and measured $\lambda_{h}$. This is useful for comparison of 'measured' spectral data to theoretical spectral predictions of these waves. The intrinsic wave data was then tabulated and plotted in an AGW spectral domain plot with boundary constraints of the Brunt-Vaisala period and molecular diffusion [Gardner, 1994]. 
In this study then, we are compensating for the Doppler affect to the observed horizontal phase velocity which results from the wind at the altitude of the airglow layers where the waves are observed and the movement of the aircraft. We have not corrected for the possible Doppler effect resulting from a moving source, such as a tropospheric frontal boundary, since the specific sources are not known.

\section{Observations}

Figure 1 is a plot of the radiance in the zenith sky from the Michelson Interferometer measurement of the $\mathrm{OH}$ Meinel $(3,1)$ band for the flight. We note that the entire flight path showed active AGW modulation to the $\mathrm{OH}$ intensity, with large $\mathrm{OH}$ $(3,1)$ wave amplitudes. Secondly we note that $N$ of $26-27^{\circ}$, the apparent horizontal wavelength was longer than that to the south with the shortest apparent wavelengths within $5^{\circ}(\sim 500$ $\mathrm{km}$ ) of Haleakala. Figure 2 (a) is an all-sky Time Difference (TD) image [see Swenson and Espy, this issue and reference] for 10:33 UT which is one of 6 images analyzed in detail, the positions of which are noted on Figure 1. Figure 2(b) is a geographic projection of the center portion of $2(a)$ with a $150 \times 150 \mathrm{~km}$ grid super imposed to highlight the geographical dimension of the structure. The images are rotated so that $N$ is up and $E$ is right in the projection. The time difference (TD) images provide contrast enhancement to wave structure. The raw images (not shown) were inspected and compared with the TD images to insure that spurious structure was not being introduced by the TD method.

The observed wave features from all of the images analyzed are summarized in Table 1 . The left columns characterize the times and range the aircraft was from Haleakala and the right columns characterize the observed wave parameters. The horizontal wavelengths $\left(\lambda_{h}\right)$ and phase front direction (normal to the direction of propagation) were measured from the geographic projections of the phase fronts (Figure 2). The airglow amplitudes of wave structure $(\Delta \mathrm{I} / \mathrm{I})$ were measured from plots of signal in the raw images with an assumption that $25 \%$ of the image signal is background. This background value assumption was corroborated through comparison of signals observed by the Michelson Interferometer vs. imager response

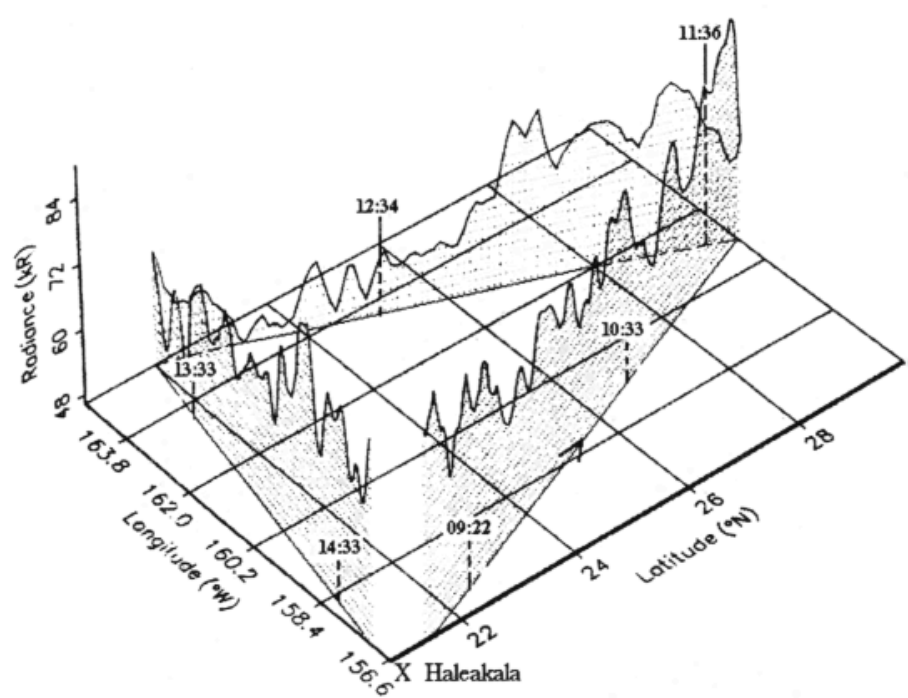

Figure 1. A plot of the zenith intensity data from the aircraft Michelson Interferometer showing the $O H$ Meinel $(3,1)$ band. Note that north of $26^{\circ}$, the wave airglow amplitude in wave structure is brighter and the apparent wavelength is longer, than south of this latitude. The six positions identified with UT time describe the location for which geographic projections of $\mathrm{OH}$ airglow imagery were analyzed, the results of which are summarized in Table 1 . An image example for the 10:33 UT time is shown in Figure 2.

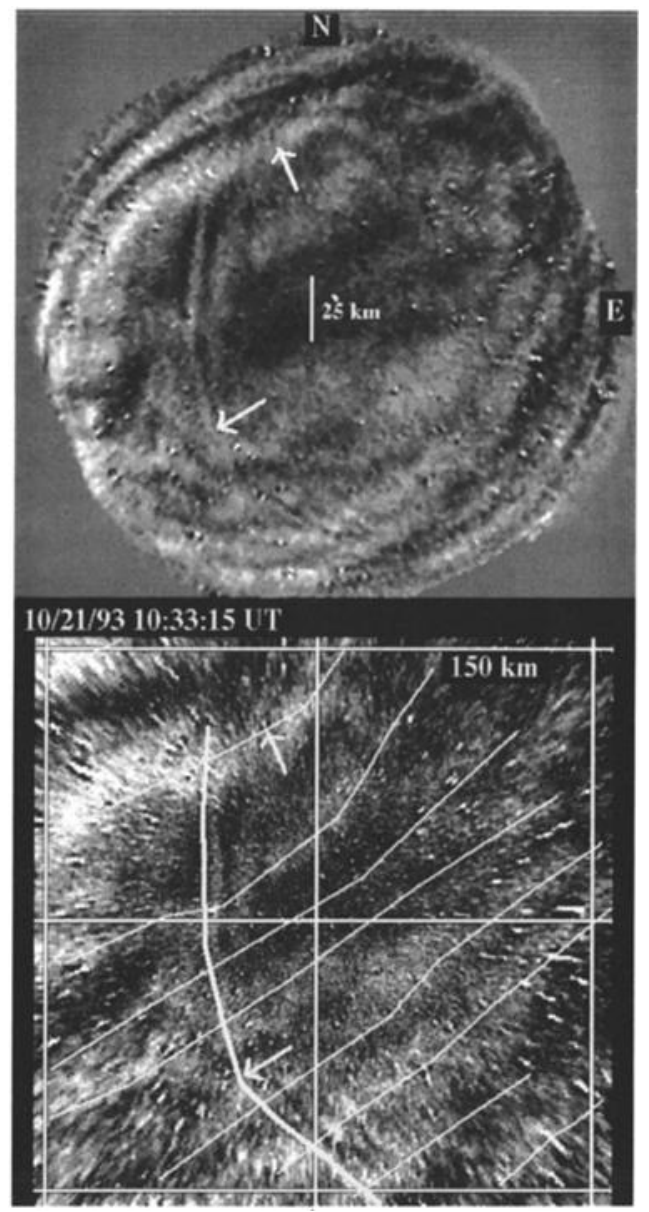

Figure 2. (a) An all-sky image for 10:33 UT with $N$ at the top and $E$, right. The top arrow shows the direction of propagation of the NW wave, with phase fronts normal to the wave. The lower arrow identifies a single curved feature which is propagating to the $S W$. The image was filtered to reduce pixel noise. (b) A geographic projection of the center of 2(a) with a $150 \mathrm{~km}$ grid superimposed. Lines have been drawn to highlight the phase fronts, the thin lines for the NW propagating wave and the thick line for the SW propagating wave.

to OH AGW features. The reader is referred to Swenson and Mende [1994] for details regarding the background. For each image, there are 2-3 monochromatic features present.

The extraction of $A G W$ observed phase velocities $\left(C_{\text {obs }}\right)$ are determined by observing the time history of AGW phase fronts in a stationary reference frame. Similarly, the method of measuring the $\mathrm{C}_{\text {obs }}$ from the aircraft observations involves multiple observations of a given AGW phase front for a significant fraction of a wave period (10-30 minutes). This apparent movement is accurately compensated for the aircraft velocity in order to calculate the intrinsic wave speed $\left(C_{i n}\right)$ in the geographic (stationary) reference frame. Since this is the first time (to our knowledge) airglow AGW structure has been imaged from an aircraft, the method of extracting $\mathrm{C}_{\text {obs }}$ from the observations requires explanation. The method employed here used stack plots of signal versus zenith angle at a fixed azimuth in the all-sky images. This method is similar to that used in Keogram plots of auroral all-sky imagery [Eather et al., 1976]. Wave positions were established for the aircraft zenith angles at $+60^{\circ}$ in the fore-aft (F-A) direction and the portstarboard (P-S). The observed component of phase velocity in the flight direction is given by $\mathrm{C}_{\mathrm{in}, \mathrm{F}-\mathrm{A}}=\left(2 \cdot \mathrm{h}_{\mathrm{OH}} \cdot \operatorname{Tan} 60^{\circ} / \mathrm{t}_{\mathrm{F}-\mathrm{A}}\right)+$ $\mathrm{V}_{\mathrm{ac}}$ where $\mathrm{h}_{\mathrm{OH}}=$ altitude of $\mathrm{OH}$ airglow $\sim 87 \mathrm{~km}, \mathrm{t}_{\mathrm{F}-\mathrm{A}}=$ time 
Table 1. Gravity wave characteristics for observations at six image positions in the flight.

\begin{tabular}{|c|c|c|c|c|c|c|c|c|c|}
\hline $\begin{array}{l}\text { Time } \\
\text { (UT) }\end{array}$ & $\begin{array}{l}\text { Halea. } \\
\text { Range (km) }\end{array}$ & $\begin{array}{l}\lambda_{\mathrm{h}} \\
(\mathrm{km})\end{array}$ & $\begin{array}{l}\lambda_{\mathrm{z}}^{*} \\
(\mathrm{~km})\end{array}$ & $\begin{array}{l}\text { Dir. of } \\
\text { Prop. ( })\end{array}$ & $\begin{array}{l}\mathrm{C}_{\mathrm{obs}} \\
\left(\mathrm{ms}^{-1}\right)\end{array}$ & $\begin{array}{l}\mathbf{T}_{\text {obs }} \\
(\min )\end{array}$ & $\begin{array}{l}C_{\text {in }} \\
\left(\mathrm{ms}^{-1}\right)\end{array}$ & $\begin{array}{l}T_{\text {in }} \\
(\min )\end{array}$ & $\begin{array}{l}\Delta \mathrm{I} / \mathrm{I}, \\
(\%)\end{array}$ \\
\hline 09:22 & 228 & $\begin{array}{l}50 \\
30\end{array}$ & 16.3 & $\begin{array}{l}340 \\
340\end{array}$ & $\begin{array}{l}35 \\
\text { Unk }\end{array}$ & $\begin{array}{l}24 \\
\text { Unk }\end{array}$ & 54.4 & 15.3 & $1-2$ \\
\hline $10: 33$ & 735 & $\begin{array}{l}80 \\
40 \\
\text { Curve \& }\end{array}$ & 5.6 & $\begin{array}{l}325 \\
325\end{array}$ & $\begin{array}{l}35 \\
\text { Unk. }\end{array}$ & $\begin{array}{l}38 \\
\text { Unk. }\end{array}$ & 18.6 & 71.7 & $\begin{array}{l}1-2 \\
1-4 \\
\end{array}$ \\
\hline 11:36 & 1059 & $\begin{array}{l}75 \\
75 \\
\end{array}$ & $\begin{array}{l}3.5 \\
29 \\
\end{array}$ & $\begin{array}{l}330 \\
15 \\
\end{array}$ & $\begin{array}{l}35 \\
116 \\
\end{array}$ & $\begin{array}{l}36 \\
11 \\
\end{array}$ & $\begin{array}{l}11.9 \\
96.2 \\
\end{array}$ & $\begin{array}{l}105 . \\
13 .\end{array}$ & $\begin{array}{l}1-2 \\
2-3 \\
\end{array}$ \\
\hline $12: 34$ & 885 & $\begin{array}{l}(\sim 75) \\
75 \\
\end{array}$ & 17 & $\begin{array}{l}340 \\
210 \\
\end{array}$ & $\begin{array}{l}\text { Unk } \\
40 \\
\end{array}$ & $\begin{array}{l}\text { Unk } \\
31 \\
\end{array}$ & 56.6 & 22. & $\begin{array}{l}1-3 \\
1 \\
\end{array}$ \\
\hline $13: 33$ & 745 & $\begin{array}{l}60 \\
65 \\
\end{array}$ & $\begin{array}{l}12 \\
5.9 \\
\end{array}$ & $\begin{array}{l}325 \\
220 \\
\end{array}$ & $\begin{array}{r}30 \\
25 \\
\end{array}$ & $\begin{array}{r}33 \\
43 \\
\end{array}$ & $\begin{array}{l}40.6 \\
19.7 \\
\end{array}$ & $\begin{array}{l}24.6 \\
55 . \\
\end{array}$ & $\begin{array}{l}1-3 \\
1-3 \\
\end{array}$ \\
\hline $14: 33$ & 257 & $\begin{array}{l}75 \\
80 \\
\text { 13-Ripple }\end{array}$ & $\begin{array}{l}11.2 \\
4.5\end{array}$ & $\begin{array}{l}305 \\
220 \\
\text { Unk }\end{array}$ & $\begin{array}{l}30 \\
25 \\
\text { Unk }\end{array}$ & $\begin{array}{l}42 \\
53 \\
\text { Unk }\end{array}$ & $\begin{array}{l}37.4 \\
15.1\end{array}$ & $\begin{array}{l}33.4 \\
88 .\end{array}$ & $\begin{array}{l}1-3 \\
1-3 \\
2\end{array}$ \\
\hline
\end{tabular}

${ }^{*}$ Computed from $\lambda_{\mathrm{z}}=\mathrm{N} \cdot \mathrm{C}_{\mathrm{in}}$, where $\mathrm{N}$ is the Brunt-Vaisala period.

\& A single curved wave structure appeared had a phase front arc length of $400 \mathrm{~km}$ and an apparent diameter of $\sim 400 \mathrm{~km}$, with the origin located in the ENE direction from the point of observation. The E-W intercept with the curved feature was $\sim 70 \mathrm{~km} \mathrm{~W}$ of the aircraft at this time. See Figure 2.

between wave transit of the $60^{\circ}$ forward and $60^{\circ}$ aft zenith

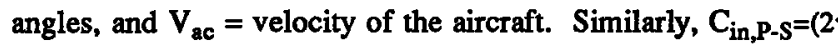
$\mathrm{h}_{\mathrm{OH}} \cdot \operatorname{Tan} 60^{\circ} / \mathrm{h}_{\mathrm{P} \text {-S }}$ ). The summary of $\mathrm{C}_{\text {obs }}$ for structures analyzed for the 6 images acquired at the times indicated in Figure 1 is tabulated in Table 1 . The measurements of the zonal and meridional wind by the $\mathrm{Na} \mathrm{W} / \mathrm{T}$ lidar were used to calculate an intrinsic phase velocity, i.e. $\mathrm{C}_{\text {in }}=\mathrm{C}_{\text {obs }}-\mathrm{U}$. The hourly averaged mean wind was calculated for the $85-90 \mathrm{~km}$ altitude region [Xin et al., this issue], where the bulk of the $\mathrm{OH}$ emission originates [Hecht et al., 1993]. It is expected that the Haleakala wind is representative near the islands but for the distant points, larger uncertainties exist, especially since large tidal changes are noted between 09-10 UT .

An exemplary image of $\mathrm{OH}$ from Haleakala is shown in Figure 3. The SW portion of the image shows the optimum contrast for the waves propagating from the $S W$, a pattern which was observed by the aircraft throughout the spatial coverage offered by the aircraft. The image has a particularly high contrast image of the NW propagating wave in the $N$ half the image, with a horizontal wavelength of $\sim 25 \mathrm{~km}$.

\section{Discussion.}

The monochromatic, planar structures observed during the October 21 flight were a dominating feature in all imagery taken during the $-3000 \mathrm{~km}$ flight. The NW propagating structure was viewed throughout the flight and simultaneously at the island. The flight path combined with the projection of the imager shows this extent to be $\sim 1 \mathrm{M}(\mathrm{km})^{2}$, or $\sim 8^{\circ} \times 10^{\circ}$ (great circle). The extensive monochromatic structures propagate and display planar, undisturbed phase fronts.

The first wave feature for each time (shown in Table 1) is the NW propagating feature which was seen throughout the flight. During the SW heading, the phase fronts and direction of propagation of the AGW feature rotated counterclockwise as the aircraft flew from NW of Haleakala to $E$ of Haleakala. The rotation of the phase fronts observed from the aircraft during the inbound leg and from the Haleakala imager suggest an origin not too distant ( 100's of km) SE of Haleakala. For the last half of the flight, a wave structure was observed propagating to the SW (see Table 1) which appeared to have a source NE of Haleakala. Note the single, curved feature in the first flight leg highlighted in the 10:33 image in Figure 2. As the aircraft proceeded to the SW (after 12:00 UT, 1.5 hours later), the sky was filled with the SW propagating wave for which the Figure 2 'curved feature' may have been the leading edge. In order to trace the wave source to its tropospheric origin (or to any other source altitude), the wind field in the intervening altitudes are required and analysis is continuing for a future publication. The SW propagating waves do not show structure change, on the average, with the NW propagating waves (i.e. there does not appear to be a wave-wave interaction). The one exception to large scale monochromatic structure was a region of localized ripples $\left(-4000 \mathrm{~km}^{2}\right)$ near Kauai, HA where the bright crests were nested between and normal to the large scale waves (not shown).

A number of localized features were identified in the imagery which did not cover major sky area. Temporally this

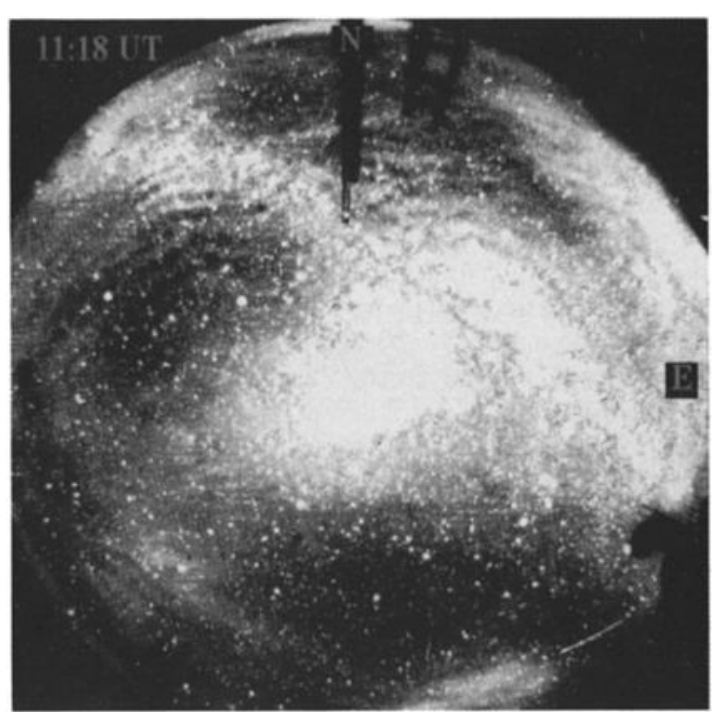

Figure 3. An exemplary all-sky projections of ground based Haleakala $\mathrm{OH}$ image data showing wave structure at that location at a time $\sim 2$ hours into the flight. The structure in the SW is a planar waves with NW-SE aligned phase fronts. Analysis of the position change of the phase fronts in sequential images at these times shows these structures are moving to the SW. In the left image, a shorter wavelength structure is propagating to the NNW, with a horizontal wavelength of $\sim 25 \mathrm{~km}$. 


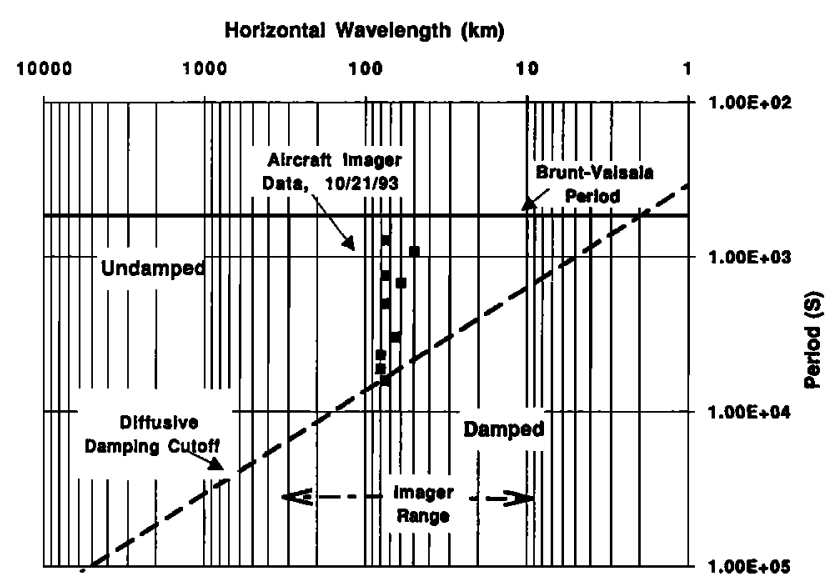

Figure 4. A log-log plot with Horizontal Wavelength (km) vs. Period (s). The wave structures identified in the images (Figure 2) were measured and plotted. The boundaries defined by the Brunt-Vaisala period and that of diffusive damping

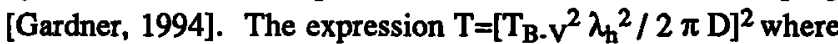
$\mathrm{D}=350 \mathrm{~m}^{2} \mathrm{~s}^{-1}$ is plotted.

included the single curved feature shown in Figure 2 , which actually may have been the leading edge of the major SW propagating system discussed above. Near the northern extent of the flights, a fast, planar, monochromatic wave was observed propagating to the $\mathrm{NE}$, with a $\mathrm{C}_{\text {in }} \sim 100 \mathrm{~ms}^{-1}$. Just prior to descent during the inbound leg, the ripple structure noted in the previous paragraph was observed. The composite set of $\lambda_{h}$ versus $C_{i n}$ observed from the aircraft on Oct 21, 1994, is plotted in Figure 4 bounded by the Brunt-Vaisala period and the diffusive damping cutoff as predicted by diffusive filtering theory [Gardner, 1994]. The diffusive damping cutoff assumes an eddy diffusivity of $350 \mathrm{~m}^{2} \mathrm{~s}^{-1}$.

\section{Summary}

The aircraft imager observed prevailing, planar, monochromatic features with horizontal wavelengths $\sim 25-80$ $\mathrm{km}$, with apparent phase velocities of $30-40 \mathrm{~ms}^{-1}$ propagating toward the NNW, over the entire area. A second monochromatic feature with a similar wavelength, was evident over all but the western half of the region explored, with an intrinsic phase velocity of $25-40 \mathrm{~ms}^{-1}$ directed toward the SW. The intrinsic wave parameters for the spatially extensive horizontal AGW structure data described here is presented in an AGW spectral domain plot and found to be consistent with the boundary defined by the Brunt-Vaisala period (at the short period extreme) and the diffusive filtering limit [Gardner, 1994]. In subsequent studies, we plan to add data from other ALOHA-93 missions to the data presented here in Figure 4.

Acknowledgments. The observations were supported by the National Science Foundation, Atmospheric Sciences
Division-Aeronomy. The team is indebted to the NCAR Electra ground and flight crew and the outstanding observational opportunity provided. G. Swenson also received partial support from Lockheed Internal Research.

\section{References}

Dao, P. D., R. Farley, X. Tao and C. S. Gardner, Lidar observations of tidal perturbations in the temperature profile between 25 and $103 \mathrm{~km}$, Geophys. Res. Lett., This Issue, 1995.

Eather, R. H., S. B. Mende, and R. J. Judge, Plasma injection of synchronous orbit and spatial and temporal auroral morphology, J. Geophys. Res., 81, 2805-2824, 1976.

Gardner, C. S., Diffusive filtering theory of gravity wave spectra in the atmosphere, J. Geophys. Res., 99, 2060120622, 1994.

Gardner, C. S., Introduction to the ALOHA/ANLC-93 campaign, Geophys. Res. Lett., This Issue, 1995.

Gardner, C. S., J. Quian, M. Coble, G. C. Papen, G. R. Swenson, and P. J. Espy, High resolution observations of density and temperature horizontal wave number spectra during the 21 October flight, Geophys. Res. Lett., This Issue, 1995.

Hecht, J. H., T. J. Kane, R. L. Walterscheid, C. S. Gardner, and C. A. Tepley, Simultaneous nightglow and $\mathrm{Na}$ lidar observations at Arecibo during the AIDA-89 campaign, $J$. Atmos. Terr. Phys., 55, 409-423, 1993.

Hines, C. O. and D. W. Tarasick, Gravity waves in airglow studies, Planet. Space Sci., 35, 851-866, 1987.

Swenson, G. R. and S. B. Mende, $\mathrm{OH}$ emission and gravity waves (including a breading wave) in all-sky imagery from Bear Lake, UT., Geophys. Res. Lett., 21, 2239-2242, 1994.

Swenson, G. R. and P. J. Espy, Observations of 2Dimensional Airglow Structure and $\mathrm{Na}$ Density from the ALOHA, October 9, 1993 'Storm Flight', Geophys. Res. Lett., This Issue, 1995.

Taylor, M. J. and M. A. Hapgood, Identification of a thunderstorm as a source of short period gravity waves in the upper atmospheric nightglow emission, Planet. Space Sci., 36, 975-985, 1988.

G. R. Swenson, Lockheed Research and Development, D91-20, B255, 3251 Hanover Street, Palo Alto, CA 94304. (e-mail: Swenson@agena.space.lockheed.com )

M. J. Taylor and P. J. Espy, Utah State University, Space Dynamics Laboratory, Logan, UT 84322-4140 (email: sdlpespy@cc.usu.edu and taylor@zeus.sdl.usu.edu)

C. Gardner and X. Tao, University of Illinois, Department of Computer and Electrical Engineering, CSRL, 1308 W. Main Street, Urbana, IL 61801 (email: cgardner@uiuc.edu, xtao@uiuc.edu)

(Received November 28, 1994 revised:July 24, 1995 accepted:August 3, 1995) 